\title{
THE CELL-FREE DNA DETECTION AND ANALYSIS AS THE NEW NON-INVASIVE PRENATAL DIAGNOSTICS OPTION
}

\author{
Maja Milojković, Jelena Milenković \\ Institute of Pathophysiology, Faculty of Medicine, University of Niš, Serbia
}

\begin{abstract}
Screening procedures for chromosomal abnormalities in fetuses are a standard of care for pregnant women. Ultrasound and maternal serum analysis are traditional prenatal screening methods with detection rates between 75\%-95\%, and considerable false-negative and false-positive results. Also, both require follow up by invasive diagnostic tests in screen-positive cases, mostly amniocentesis and chorionic villi sampling, which are associated with notable risk of pregnancy loss. One of the innovative non-invasive prenatal testing (NIPT) options is the analysis of cell-free DNA (cfDNA) in plasma, which is detected in maternal circulation in a relatively high concentration. Commercial tests for cfDNA in maternal blood have recently become available. Cell-free DNA detection tests do not separate fetal from maternal DNA but use full cfDNA complement and analyze difference in total amount of sequenced DNA fragments, with the help of sophisticated data analysis software. It seems that cfDNA technology testing is highly accurate and has a very high sensitivity, so the difference compared to routine serum sample screening shows its significant superiority. However, cfDNA positive results still need confirmation by the invasive testing. The cell-free DNA analysis aims to become the first choice NIPT option due to its safety and high accuracy rate. The final goal is to develop the reliable method that could eventually replace invasive prenatal testing procedures.
\end{abstract}

Key words: $c f D N A$, aneuploidy, prenatal diagnosis, amniocentesis, chorionic villi sampling, maternal-fetal exchange.

\section{Introduction}

A standard care for pregnant women includes the use of prenatal diagnostic tests. Screening procedures are done early in pregnancy in order to identify the presence of chromosomal abnormalities, especially aneuploidies. These anomalies are the most common factor causing the failure of an embryo's growth and normal development of fetus. The most frequent chromosome abnormalities in miscarriages include trisomy or monosomy for chromosomes 13 (Patau syndrome, T13), 15, 16, 18 (Edwards syndrome, T18), 21 (Down syndrome, T21), or 22, as well as triploidy and abnormalities of sex chromosomes. Most fetuses with aneuploidies succumb to an early miscarriage, and only few percent survive to the newborn period, but may suffer significant morbidity and mortality $[1,2]$.

The prenatal diagnostic techniques comprise noninvasive diagnostics - ultrasonography (nuchal translucency) and maternal serum screening (alphafetoprotein, estriol, beta-hCG) and invasive diagnostic methods - amniocentesis (AC) and chorionic villus sampling test (CVS). Ultrasound and maternal serum analysis are considered to be screening procedures that

${ }^{*}$ Correspondence to: Maja Milojković, M.D., PhD

Nade Tomić 21, 18000 Niš

Phone: +381641125452

E-mail: maja@medfak.ni.ac.rs

Received February $27^{\text {th }}, 2017$, accepted for publication May $8^{\text {th }}, 2017$ both require follow up by $\mathrm{CVS}$ or $\mathrm{AC}$ in screen-positive cases for a definitive diagnosis of a chromosome abnormality in the fetus. Invasive procedures are associated with notable risk of pregnancy loss, thus most female do not undergo the procedures unless there is a high risk indication. Invasive prenatal diagnosis is not a feasible option for all low-risk mothers and would eventually cause more miscarriages than detection of aneuploidy [3-5].

In order to improve the efficiency of non-invasive prenatal diagnostics and reduce the risk of currently available invasive procedures, the creation of novel, more sophisticated methods is of primary importance. Considerable effort has been devoted to developing a more accurate, reliable and safe non-invasive prenatal testing (NIPT), that would have a high detection rate $(\sim 95 \%)$ and low false-positive rate $(\sim 1 \%)$ [2].

In 2012 the American Congress of Obstetricians and Gynecologists (ACOG) approved the use of noninvasive testing of cell-free fetal DNA (cfDNA) in maternal circulation for women at high risk [6]. Since then, numerous reports on the use of cfDNA for NIPT have been published, and a number of commercial products were created [7].

Prenatal tests using cfDNA analysis are especially suitable for detection of chromosomal aneuploidies, trisomy or monosomy. Sex chromosomes aneuploidies (45, X0 - Turner syndrome, XXY - Klinefelter syndrome, and triple $\mathrm{X}$ syndrome) can also be detected with this method [2]. 
The objective of this review is to present current knowledge and describe newly developed methods for application of cfDNA detection and analysis as the new NIPT option.

\section{Traditional Prenatal Screening Methods}

Non-invasive prenatal screening, recommended by the ACOG and the American College of Medical Genetics, includes a combination of first trimester risk assessment (FTRA) [11-14 weeks), maternal serum analyte (quad) screening (15-20 weeks), and a sonographic fetal structural survey (18-22 weeks). These tests are safe for the pregnancy but their primary target is detection of T21. The first trimester risk assessment and quad screening generally provide an adjusted risk for the presence of fetal aneuploidy. A sonographic fetal survey may suggest fetal aneuploidy by identifying so-called soft markers, with greater accuracy if several of these markers are present $[3,5,8]$.

Detection rates of traditional prenatal screening methods are between $75 \%$ and $96 \%$ with considerable false-negative rates between $12-23 \%$ and false-positive rates ranging from $5 \%$ to $10 \%$. If the results are positive, further checkup and confirmation is needed by direct genetic testing [3,5,8-11].

A definitive prenatal diagnosis of fetal aneuploidy requires direct fetal cells karyotyping and genetic analysis, for which two invasive procedures are routinely applied: CVS and AC. For CVS, a biopsy of placental cells is employed. The procedure can be performed early in pregnancy (10-13 weeks) and the results are issued within the following 10 days. Besides its invasiveness, the problem with CVS lies in the cell type which is sampled for the analysis, as these cells originate from the trophoectoderm and may contain placental mosaicism $[2,12]$. For AC, the primarily derived fetal cells are gained by aspiration of amniotic fluid and further subjected to analysis. Given the high pregnancy loss rates in early AC, it is usually offered after 15 weeks of gestation. Also, a low number of harvested cells require longer culture times and thus results can be issued within 8-14 days [2,13].

The diagnostic accuracy of karyotyping for specified invasive tests was found to be $97.5 \%$ to $99.8 \%$ [14,15]. Estimation of procedure-related miscarriage risk is $1 \%$ for CVS, while AC is regarded as a safer procedure with $1 / 300$ to $1 / 600$ risk [4,5,16-18]. In 2015, Akolekar et al. [19] reported in a systematic meta-analysis that the procedure-related risks of miscarriage for these invasive procedures are $0.81 \%$ and $2.18 \%$ for $\mathrm{AC}$ and CVS, respectively.

Cytogenetic analyses, ensuing invasive procedures, comprise fluorescence in situ hybridization (FISH) method and chromosomal microarray analysis (CMA). With FISH method, the results are available within 24 to 48 hours. The sensitivity and specificity of FISH is estimated between $99.6 \%$ and $99.98 \%$. Disadvantage of the method is that it identifies only the most frequent cytogenetic abnormalities, thus the FISH should always be followed by routine chromosome analysis [20]. Besides detection of chromosome number abnormalities, CMA testing provides results for chromosomal imbalances (copy number variants) such as microdeletions and microduplications and unbalanced rearrangements of chromosome segments [21,22].

\section{Fetal Cells and Cell-free DNA in Prenatal Diagnostics}

At first, analysis of fetal cells in maternal blood was considered as a promising new candidate for noninvasive prenatal diagnostics. The possibility of their isolation and study for early chromosomal abnormalities in the first and second trimester provided exciting new opportunities for NIPT [2].

During pregnancy, fetal and maternal cells are exchanged across placenta [23]. It is suggested that this process has a physiological role in the development of maternal tolerance to the fetus. The precise mechanism by which this occurs is still unclear. Some of the proposed mechanisms include micro-traumatic rupture of the placental blood channels or leakage of placentauterine barrier, adhesion and transmigration across high endothelial venulae, and other [24,25].

There are several types of fetal cells detected in maternal blood during pregnancy. Cells that are most frequently found and examined are nucleated red blood cells or erythroblasts, CD34+ hematopoietic progenitors, trophoblasts, lymphocytes, and granulocytes. A fetomaternal microchimerism created in this way may persist for the lifetime [26,27].

However, there are specific disadvantages in management of all these cell types [26]. The major problem for successful usage of the cells is their scarcity in maternal blood (one fetal cell on every $10^{5}-10^{9}$ maternal cells after the first trimester). This requires special techniques for their enrichment in maternal blood sample before any further analysis. Many different cell isolation methods have been developed in order to obtain the successful quantity of fetal cells (flow cytometry, density gradient centrifugation, micromanipulation), but all the methods require high technical approaches and still provide low yield $[2,28]$.

However, it was shown in 1997 that fetal cell-free DNA could be detected in maternal circulation, with relatively high mean concentration in total plasma DNA $(3.4 \%-6.2 \%)$. This is 20 to 25 times greater level of fetal DNA in plasma compared to the DNA extracted from fetal cellular fraction [29,30].

The fetal cfDNA originates from the fetoplacental unit cells in the circulation or from various fetal organ systems. The main mechanism of fetal cfDNA release is supposed to be related to apoptosis of trophoblasts, as a result of normal aging, although an accidental breakage or necrosis may be the reasons as well [30]. This process is present continuously during pregnancy as early as from 5-7 weeks. The fetal fraction of cfDNA is lower in the earlier gestational age. Certain physiological 
systems remove free DNA from the circulation within a few hours $[16,31,32]$. Additionally, very rapid clearance of fetal DNA occurs following delivery, which confirms the presumption that the most of fetal cfDNA in maternal circulation is derived from placenta [33].

Commercial tests for cfDNA in maternal blood have recently become available. Currently, a number of companies are trying to develop an optimal commercial product that could use cfDNA for fetal chromosome aneuploidies analysis. The absolute amount of fetal cfDNA is very small (less than $1 \mathrm{mg} / 20 \mathrm{ml}$ of whole blood), which makes the separation of fetal cfDNA from maternal cfDNA technically challenging. That is why methods for their separation are dismissed and investigations are turned to the approaches that would use full cfDNA complement. Full cfDNA sequencing and sophisticated data analysis would detect abnormal amounts of chromosome specific DNA loci in the presence of fetal aneuploidy. The method of fetal cfDNA analysis was proved to be less demanding compared to isolation of fetal cells $[7,11,31]$.

\section{Methods of cfDNA Detection and Analysis}

The first methods which have been employed for gathering and analysis of cfDNA were massively parallel shotgun sequencing (MPSS) and targeted sequencing. Both approaches use next generation sequencing technique, with high levels of sensitivity and accuracy for reliable analysis of the small cfDNA amounts [2].

The MPSS is a quantitative test, which relies on detecting difference in the total amount of plasma DNA fragments, while not distinguishing maternal from fetal DNA. The MPSS technique is based on the sequencing of large numbers of small DNA sequences (25-36 bp in length) from the entire genome. In the setting of NIPT, it would mean the sequencing of the whole amount of cfDNA from maternal plasma, or tens of millions of short-sequences in a single run [1,2]. After the sequencing, the chromosomal origin of each DNA fragment is determined by comparison with a reference copy of the human genome. Fragments (or reads) are categorized by chromosome, as well as their number per normal reference chromosome, which is referred to as counting. When the amount of a sequence fragment exceeds the threshold for a normal chromosome it is considered the positive result for trisomy. The increase in the quantity of genetic material occurs due to the $50 \%$ excess of genetic material originating from trisomic fetus extra chromosome [1,2,34].

This potential difference due to aneuploidy would be very small as the fetal DNA represents $10 \%$ at most of the cfDNA fraction, and the presence of extra DNA material (in T21) would change total cfDNA sample for only $0.075 \%$. Because of this small DNA amount change, a large number of reads must be made in order to achieve satisfying degree of confidence, making the whole process robust. Also, it is estimated that in order to return sufficient data from the clinically significant chromosomes $(13,18,21, \mathrm{X}$ and $\mathrm{Y}$; representing only around $14 \%$ of the genome) approximately 25 million raw sequencing reads are required per sample $[1,2$, $34,35]$.

The main limitation of MPSS is caused by the influence of GC chromosomal content on PCR amplification, leading to variability of the accuracy rate The detection of T13 and T18 is especially challenging due to high GC content on these chromosomes. This issue has been notably reduced using novel bioinformatics algorithms [34-37].

The Targeted Sequencing test selectively amplifies specific genomic regions (loci of interest) which are read and counted. This significantly reduces the total number of reads, and all amplified sequences are utilized compared to MPSS method. The focus on clinically important chromosomes (13, 18, 21, X and Y) should provide higher sensitivity and specificity for the method. Still, as with quantitative read, the detection rates vary, depending on the chromosome tested, and are highest for T21 [7,38]. Similar to the MPSS method, post-hoc data analysis requires appropriate bioinformatics platform, such as Z-score with GC correction and an internal control [2].

Starting from these two first approaches of NIPT, different companies made the effort to develop more accurate, sensitive and cost effective next generation test. The clinical implications for all newly developed tests are the same - they are screening tests that use a sample of maternal cfDNA and positive results still must be confirmed by invasive testing (CVS and AC).

One of the advanced techniques is called Digital Analysis of Selected Regions (DANSR). This is a targeted sequencing approach that initially amplifies specific chromosome loci of interest and then uses counting similar to MPSS analysis. It is coupled with post-hoc bioinformatics algorithm (Fetal Fraction Optimized Risk of Trisomy Evaluation - FORTE) that accounts for agerelated risks and fetal fraction. This approach has greater efficiency than MPSS alone [38].

Another approach - Parental Support (PS) combines a targeted amplification, measuring single nucleotide polymorphisms (SNPs), and sophisticated statistical analysis. In this method, the number and identity of alleles of preferred chromosomal loci are determined, after which a model set of hypotheses is calculated using Bayesian statistics. A probability to each hypothesis is estimated and considering major individual variables and fetal cfDNA fraction, individual risk score is provided [39]. In this way, the problem of chromosome amplification variability is omitted and similar accuracy of fetal copy number at chromosomes is achieved. Using PS approach it is easier to detect sex chromosome aneuploidies, which is especially important as these abnormalities represent nearly half of all chromosomal defects at-birth [40].

The results of fetal aneuploidy risk assessment using these methods can be provided within the first 2 weeks, in early pregnancy. Also, cfDNA technology testing appears to be highly accurate and to have very high sensitivity, particularly chromosome 21 aneuploidy (99\%), and the difference compared to routine serum sample screening (2-4\% for T21) shows its significant superiority 
[2,6,11]. Out of aneuploidies, Down syndrome has the highest incidence and it is the single most common cause of mental retardation accompanied by serious health disorders. Accuracy of its detection varies depending on a technical approach of a company. The sensitivity and specificity range from $98.6-100 \%$ and $99.8-100 \%$ for $\mathrm{T} 21,97.2-100 \%$ and $99.7-100 \%$ for $\mathrm{T} 18,78.6-100 \%$ and $99.0-100 \%$ for $\mathrm{T} 13$ [2,36,39].

Proposed indications for NIPTs and cfDNA analysis for aneuploidy are: maternal age above 35 years, fetal ultrasound findings indicating an increased risk, maternal serum screening test showing an increased risk, previous pregnancy with birth defects in child, family history of aneuploidy, positive test result for aneuploidy, parental balanced Robertsonian translocation. Testing can be performed as early as 9 weeks' gestation. However, positive results should be followed up with CVS or AC. What remains to be investigated is the accuracy of cfDNA method as NIPTs for females who are in the low risk population $[6,28]$.

Additionally, economic evaluation of newer NIPT methods is important in order to be accepted for wider clinical use. In the study by Song et al. [11], the costeffectiveness model of NIPT for high-risk women in US population was assessed. The results showed better T21 detection and reduced unnecessary invasive procedures that lower the rate of euploid fetal losses, bringing to the lower total healthcare expenditures.

The new generation non-invasive prenatal screening for microdeletion syndromes test $\left(\right.$ Panorama ${ }^{\mathrm{TM}}$ ) incorporates maternal genotypic information, thus differentiating fetal genotypes in the plasma. It targets and analyses 19.488 SNPs from chromosomes 21, 18, 13, X, and Y. Additionally, the targeted screening was expanded for five microdeletion syndromes, by including SNPs within the microdeletion regions-of-interest [41]. The Panorama Extended Panel offers a risk evaluation for the 22q11.2 deletion (DiGeorge), 1p36 deletion, Cri-du-chat, Prader-
Willi, and Angelman deletions. The sensitivity of this test was assessed to be greater than $93 \%$ and specificity greater than $99 \%$. The importance of this test is emphasized by fact that these syndromes have very low detection rates by traditional screening tests, the risk for microdeletions is independent of maternal age, and their incidence is often underestimated. The evaluated combined incidence of these syndromes using Panorama test was calculated to be about $1 / 1000$, showing that the incidence of DiGeorge syndrome is higher than for cystic fibrosis. All these circumstances assert the need for inclusion of microdeletion syndromes in prenatal screening options [41].

Besides the determination of the fetal aneuploidy risk, levels of circulating cfDNA are recognized as a marker of several pregnancy related complications. cfDNA levels were increased in preeclampsia, intrauterine growth restriction, preterm labor, placenta previa and hyperemesis gravidarum. Increased leakage of the cells is reported in the cases of fetal aneuploidy and preeclampsia. Because cfDNA levels decrease during diseases progression, it is suggested that they can be a predictive marker for early detection of these disorders $[30,42]$.

\section{Conclusion}

Cell-free fetal DNA in maternal blood is a valuable source of genetic information which has become increasingly available due to the progress in DNA sequencing and bioinformatics' techniques. The non-invasive prenatal testing with cfDNA represents the new generation of prenatal diagnostic screening, which strives to become the first choice testing option due to its safety and high accuracy rate. The final goal is to develop a feasible and reliable method that could eventually replace invasive prenatal testing.

\section{References}

1. Lo YM. Non-invasive prenatal diagnosis by massively parallel sequencing of maternal plasma DNA. Open Biol 2012; 2: 120086.

2. Norwitz ER, Levy B. Noninvasive prenatal testing: the future is now. Rev Obstet Gynecol 2013; 6:48-62.

3. ACOG committee on practice bulletins. ACOG Practice Bulletin No. 77: screening for fetal chromosomal abnormalities. Obstet Gynecol 2007; 109:217-227.

4. ACOG committee on practice bulletins. ACOG Practice Bulletin No. 88, December 2007. Invasive prenatal testing for aneuploidy. Obstet Gynecol 2007; 110:1459-1467.

5. Driscoll DA, Gross, SJ. Professional Practice Guidelines Committee. Screening for fetal aneuploidy and neural tube defects. Genet Med 2009; 11:818-821.

6. ACOG committee on practice bulletins. ACOG Committee on Genetics. Committee Opinion No. 545: Noninvasiveprenatal testing for fetal aneuploidy. Obstet Gynecol 2012; 120:1532-1534.

7. Palomaki GE, Kloza EM, Lambert-Messerlian GM, Haddow JE, Neveux LM, Ehrich M, Van den Boom D, Bombard AT, Deciu C, Grody WW, Nelson SF Canick JA. DNA sequencing of maternal plasma to detect Down syndrome: an international clinical validation study. Genet Med 2011; 13:913-920.

8. Cuckle H, Benn P, Wright D. Down syndrome screening in the first and/or second trimester: model predicted performance using metaanalysis parameters. Semin Perinatol 2005; 29:252-257.

9. Nicolaides $\mathrm{KH}$, Nuchal translucency and other firsttrimester sonographic markers of chromosomal abnormalities. Am J Obstet Gynecol 2004; 191:45-67.

10. Spencer K, Spencer CE, Power M, Dawson C, Nicolaides KH. Screening for chromosomal abnormalities in the first trimester using ultrasound and maternal serum biochemistry in a one-stop clinic: a review of three years prospective experience. BJOG 2003; 110:281-286.

11. Song K, Musci TJ, Caughey AB. Clinical utility and cost of non-invasive prenatal testing with cfDNA analysis in high-risk women based on a US population. J Matern Fetal Neonatal Med 2013; 26:1180-1185.

12. Coman D, Gardner RJ, Pertile MD, Kannu P. Trisomy 16 mosaicism at chorionic villus sampling and amniocentesis with a normal physical and intellectual outcome. Fetal Diagn Ther 2010; 28:117-118.

13. Hodor JG, Poggi SH, Spong CY, Goodwin KM, Vink JS, Pezzullo JC, Ghidini A. Risk of third-trimester amniocentesis: a case-control study. Am J Perinatol 2006; 23:177-180. 
14. Wapner RJ, Martin CL, Levy B, Ballif BC, Eng CM, Zachary JM, Savage M, Platt LD, Saltzman D, Grobman WA, Klugman S, Scholl T, Simpson JL, McCall K, Aggarwal VS, Bunke B, Nahum O, Patel A, Lamb AN, Thom EA, Beaudet AL, Ledbetter DH, Shaffer LG, Jackson L. Chromosomal microarray versus karyotyping for prenatal diagnosis. N Engl J Med 2012; 367: 2175-2184.

15. Choy KW, Kwok YK, Cheng YK, Wong KM, Wong HK, Leung KO, Suen KW, Adler K, Wang CC, Lau TK, Schermer MJ, Lao TT, Leung TY. Diagnostic accuracy of the BACs-onBeads $^{\mathrm{TM}}$ assay versus karyotyping for prenatal detection of chromosomal abnormalities: a retrospective consecutive case series. BJOG 2014; 121:1245-1252.

16. Wright CF, Burton $\mathrm{H}$. The use of cell-free fetal nucleic acids in maternal blood for non-invasive prenatal diagnosis. Hum Reprod Update 2009; 15:139-151.

17. Mujezinovic F, Alfirevic Z., Procedure-related complications of amniocentesis and chorionic villous sampling: a systematic review. Obstet Gynecol 2007; 110:687-694.

18. Odibo AO, Gray DL, Dicke JM, Stamilio DM, Macones GA, Crane JP. Revisiting the fetal loss rate after second-trimester genetic amniocentesis: a single center's 16-year experience. Obstet Gynecol 2008; 111:589-595.

19. Akolekar R, Beta J, Picciarelli G, Ogilvie C, D'antonio F. Procedure-related risk of miscarriage following amniocentesis and chorionic villus sampling: a systematic review and metaanalysis. Ultrasound Obstet Gynecol 2015; 45:16-26.

20. Tepperberg J, Pettenati MJ, Rao PN, Lese CM, Rita D, Wyandt $\mathrm{H}$, Gersen S, White B, Schoonmaker MM. Prenatal diagnosis using interphase fluorescence in situ hybridization (FISH): 2year multi-center retrospective study and review of the literature. Prenat Diagn 2001; 21:293-301.

21. Miller DT, Adam MP, Aradhya S, Biesecker LG, Brothman AR, Carter NP, Church DM, Crolla JA, Eichler EE, Epstein CJ, Faucett WA, Feuk L, Friedman JM, Hamosh A, Jackson L, Kaminsky EB, Kok K, Krantz ID, Kuhn RM, Lee C, Ostell JM, Rosenberg C, Scherer SW, Spinner NB, Stavropoulos, DJ, Tepperberg JH, Thorland EC, Vermeesch JR, Waggoner DJ, Watson MS, Martin CL, Ledbetter DH. Consensus statement: chromosomal microarray is a first-tier clinical diagnostic test for individuals with developmental disabilities or congenital anomalies. Am J Hum Genet 2012; 86:749-764.

22. Wapner R. A multicenter, prospective, masked comparison of chromosomal microarray with standard karyotyping for routine and high risk prenatal diagnosis. Am J Obstet Gynecol 2012; 206:S2

23. Klonisch T, Drouin R. Fetal-maternal exchange of multipotent stem/progenitor cells: microchimerism in diagnosis and disease. Trends Mol Med 2009; 15:510-518.

24. Dawe GS, Tan XW, Xiao ZC. Cell Migration from Baby to Mother. Cell Adh Migr 2007; 1:19-27.

25. Engelhardt B. Molecular mechanisms involved in T cell migration across the blood-brain barrier. J Neural Transm 2006; 113: 477-485.

26. Guetta E, Simchen MJ, Mammon-Daviko K, Gordon D, Aviram-Goldring A, Rauchbach N, Barkai G. Analysis of fetal blood cells in the maternal circulation: challenges, ongoing efforts, and potential solutions. Stem Cells Dev 2004; 13:93-99

27. O’Donoghue K, Chan J, De La Fuente J, Kennea N, Sandison A, Anderson JR, Roberts IA, Fisk NM. Microchimerism in female bone marrow and bone decades after fetal mesenchymal stem-cell trafficking in pregnancy. Lancet 2004; 364:179-182.

28. Gussin HAE, Elias S. Culture of fetal cells from maternal blood for prenataldiagnosis. Hum Reprod Up 2002; 8·523-527.
29. Lo YM, Corbetta N, Chamberlain PF, Rai V, Sargent IL, Redman CW, Wainscoat JS, Presence of fetal DNA in maternal plasma and serum. Lancet 1997; 350:485-487.

30. Sifakis S, Koukou Z. Spandidos DA. Cell-free fetal DNA and pregnancy-related complications (review). Mol Med Rep 2015; 11:2367-2372.

31. Ariga H, Ohto H, Busch MP, Imamura S, Watson R, Reed W, Lee TH., Kinetics of fetal cellular and cell-free DNA in the maternal circulation during and after pregnancy: implications for noninvasive prenatal diagnosis. Transfusion 2001; 41: 1524-1530.

32. Invernizzi P, Biondi ML, Battezzati PM, Perego F, Selmi C, Cecchini F, Podda M, Simoni G. Presence of fetal DNA in maternal plasma decades after pregnancy. Hum Genet 2002 110:587-591.

33. Hahn S, Huppertz B. Holzgreve W, Fetal cells and cell-free fetal nucleic acids in maternal blood: new tools to study abnormal placentation? Placenta 2005; 26:515-526.

34. Fan HC, Blumenfeld YJ, Chitkara U, Hudgins L. Quake, SR, Noninvasive diagnosis of fetal aneuploidy by shotgun sequencing DNA from maternal blood. Proc Natl Acad Sci USA 2008, 105:16266-16271.

35. Sparks AB, Struble CA, Wang ET, Song K, Oliphant A. Noninvasive prenatal detection and selective analysis of cellfree DNA obtained from maternal blood: evaluation for trisomy 21 and trisomy 18. Am J Obstet Gynecol 2012; 206:319.e1-9.

36. Chiu RWK, Chan KC, Gao Y, Lau VYM, Zheng W, Leung TY, Foo CHF, Xie B, Tsui NBY, Lun FMF, Zee BCY, Lau TK, Cantor CR, Lo YMD. Noninvasive prenatal diagnosis of fetal chromosomal aneuploidy by massively parallel genomic sequencing of DNA in maternal plasma. Proc Natl Acad Sci USA 2008; 105:20458-20463.

37. Chen EZ, Chiu RW, Sun H, Akolekar R, Chan AKC, Leung TY, Jiang P, Zheng YWL, Lun FMF, Chan LYS, Jin Y, Go ATJI, Lau ET, To WWK, Leung WC, Tang RYK, Au-Yeung SKC, Lam H, Kung YY, Zhang X, Van Vugt JMG, Minekawa R, Tang MHY, Wang J, Oudejans CBM, Lau TK, Nicolaides $\mathrm{KH}$, Lo YMD. Noninvasive prenatal diagnosis of fetal trisomy 18 and trisomy 13 by maternal plasma DNA sequencing. PLoS One 2011; 6:e21791.

38. Ashoor G, Syngelaki A, Wang E, Struble C, Oliphant A, Song $\mathrm{K}$, Nicolaides KH. Trisomy 13 detection in the first trimester of pregnancy using a chromosome-selective cell-free DNA analysis method. Ultrasound Obstet Gynecol 2013; 41:21-25.

39. Zimmermann B, Hill M, Gemelos G, Demko Z, Banjevic M, Baner J, Ryan A, Sigurjonsson S, Chopra N, Dodd M, Levy B, Rabinowitz M. Noninvasive prenatal aneuploidy testing at chromosomes 13, 18, 21, X, and Y, using targeted sequencing at polymorphic loci. Prenat Diagn 2012; 32:1233-1241.

40. Grati FR, Barlocco A, Grimi B, Milani S, Frascoli G, Di Meco AM, Liuti R, Trotta A, Chinetti S, Dulcetti F, Ruggeri AM, De Toffol S, Clementi M, Maggi F, Simoni G. Chromosome abnormalities investigated by non-invasive prenatal testing account for approximately $50 \%$ of fetal unbalances associated with relevant clinical phenotypes. Am J Med Genet A 2010; 152A:1434-1442.

41. Hall MP, Panorama ${ }^{\mathrm{TM}}$ Non-Invasive Prenatal Screening for Microdeletion Syndromes. Nat-MD-WhitePaper-V5-NL-(4/1/14), 2014, Available from: http://www.lifelabs.com/files/WhitePaperMicrodeletion.pdf

42. Jansen MW, Korver-Hakkennes K, van Leenen D, Visser W, in 't Veld PA, de Groot CJ, Wladimiroff JW. Signifcantly higher number of fetal cells in the maternal circulation of women with pre-eclampsia. Prenat Diagn 2001; 21:1022-1026. 